\title{
Archipel
}

ARCHIPEL Études interdisciplinaires sur le monde insulindien

$98 \mid 2019$

Varia

\section{Le Soliloque des muets, un film de Stéphane Roland}

Jean-Michel Marlaud

\section{OpenEdition}

Journals

Édition électronique

URL : http://journals.openedition.org/archipel/1322

DOI : 10.4000/archipel.1322

ISSN : 2104-3655

\section{Éditeur}

Association Archipel

\section{Édition imprimée}

Date de publication : 3 décembre 2019

Pagination : 59-62

ISBN : 978-2-910513-82-5

ISSN : 0044-8613

\section{Référence électronique}

Jean-Michel Marlaud, "Le Soliloque des muets, un film de Stéphane Roland », Archipel [En ligne], 98

2019, mis en ligne le 11 décembre 2019, consulté le 16 mars 2021. URL : http://

journals.openedition.org/archipel/1322 ; DOI : https://doi.org/10.4000/archipel.1322 


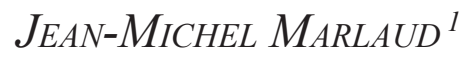

\section{Le Soliloque des muets, un film de Stéphane Roland}

Plus de 50 ans après le coup d'État de 1965 qui, en Indonésie, mit fin à la présidence de Soekarno et vit l'avènement du Nouvel Ordre de Soeharto, le réalisateur part à la rencontre des victimes de la répression et de leurs descendants. Constitué d'interviews réalisées à l'occasion d'un séjour en Indonésie et d'images d'archives issues du Tribunal populaire international organisé aux Pays-Bas en 2015, ce film² éclaire certains aspects de cet épisode de l'Histoire, aujourd'hui bien oublié, alors que le nombre des victimes et la gravité des violations des droits de l'Homme en font une des pages les plus sombres du $\mathrm{XX}^{\mathrm{e}}$ siècle.

« Sous la plage, les charniers »... Cette image vient d'elle-même à l'esprit du spectateur du documentaire de Stéphane Roland devant les paysages bucoliques de rizières ou de cocotiers, dont il apprend soudain qu'ils rejettent parfois des ossements humains au hasard de telle ou telle tempête, révélant ainsi des fosses communes, témoignages enfouis des massacres de 1965.

Mais au fond, ces paysages ne sont eux-mêmes qu'une métaphore des esprits : en Indonésie, qui aujourd'hui est prêt à revenir sur ces pages anciennes ? Par crainte ou, comme le laissent entendre quelques images fugitives, parce qu'une jeunesse avide de loisirs et de consommation n'entend pas s'intéresser à des épisodes déjà lointains ?

\section{Diplomate.}

2. Le Soliloque des muets, documentaire de Stéphane Roland, Pyramide Production, France, 2017, $70 \mathrm{mn}$. 
L'auteur se tient sur une ligne de crête étroite entre l'engagement personnel et la recherche d'objectivité.

Un engagement personnel qui s'inscrit dans un parcours d'études — la sociologie - puis d'activités professionnelles. Celles-ci, qui l'ont conduit à aborder divers métiers du cinéma (ingénieur du son, chef opérateur, image, et enfin réalisateur) lui ont permis d'acquérir une maîtrise technique qui se retrouve dans la subtile alternance entre des images aux couleurs chatoyantes et d'autres, en noir et blanc, dramatiques. Mais elles ont aussi suivi un fil conducteur que l'on pourrait qualifier de militant : ce n'est pas un hasard si l'on retrouve le nom de Stéphane Roland sur des films consacrés aux discriminations dont souffrent les gens du voyage ou aux surveillants pénitentiaires.

Cette absence de neutralité est compensée par le choix d'un travail dans la durée - cinq années de préparation -, par la volonté de s'associer à une universitaire indonésienne, Truly Hitosoro, elle-même diplômée de l'EHESS, et surtout par une démarche respectueuse des personnalités rencontrées, à qui le temps est donné de s'exprimer, de convoquer leurs souvenirs, parfois de ressusciter tel ou tel compagnon - ou compagne — de captivité. L'absence même du cinéaste, qui n'apparait jamais à l'écran et dont on n'entend même pas les questions, renforce ce sentiment d'écoute attentive.

Le film est d'abord une longue litanie de violations des droits de l'Homme, exprimées directement devant la caméra à l'occasion d'entretiens conduits en Indonésie ou bien exposées lors de la session du Tribunal populaire international pour l'Indonésie qui s'est tenue aux Pays-Bas en novembre 2015, dont plusieurs extraits figurent dans le film. Détentions sans jugement ou qui se sont prolongées au-delà de la peine fixée, tortures, exécutions sommaires, corruption, obsession de la faim, destruction de bibliothèques... La liste semble sans fin et l'arbitraire ne s'arrête d'ailleurs pas à la libération, puisqu'une mention apposée sur les documents d'identité interdit en pratique aux anciens détenus de trouver du travail.

La plupart des victimes s'expriment avec la retenue et le sourire si typiquement javanais, même pour décrire des épisodes dramatiques : l'appel quotidien de quelques compagnons de captivité qui ne reviendront jamais, avec la perspective d'être le prochain sur la liste, ou bien le souvenir de cette prisonnière déjà âgée qui, à l'occasion d'une fouille, préfère avaler toute sa provision de piment plutôt que de s'exposer à la voir confisquée et dont les yeux larmoyants interloquent ses geôliers. Parfois pourtant, le masque craque et l'émotion fait éruption, qu'il s'agisse d'un témoin devant le Tribunal populaire hurlant au souvenir des humiliations subies lorsqu'étudiante, elle fut soumise à interrogatoire et sommée de confesser son appartenance au PKI, ou du fils d'un ancien prisonnier obligé par les larmes d'interrompre son propos.

Au-delà de ce rappel de l'un des plus grands massacres du $\mathrm{XX}^{\mathrm{e}}$ siècle, $\mathrm{Le}$ Soliloque des muets suscite néanmoins plus de questions qu'il n'apporte de réponses. 
La première question, bien sûr, porte sur les raisons de cette apparente amnésie. Les victimes appartenaient au camp des perdants. On comprend donc le silence en Indonésie, dans un environnement marqué par la censure et le caractère autoritaire du régime. Mais l'ancien Président Soeharto a été renversé en 1998, il est mort en 2008, ces faits appartiennent désormais à l'Histoire. Cette interrogation se pose d'ailleurs aussi dans d'autres pays : le remarquable documentaire El silencio de otros, sorti récemment sur les écrans en France, posait la même question pour les victimes du franquisme, plus de 40 ans après la mort du dictateur et le vote de la loi d'amnistie.

Si l'on peut discerner les raisons de ce silence en Indonésie, l'attitude de la communauté internationale est encore plus surprenante. Le choix du titre du film, Le Soliloque des muets, est un hommage à un texte de Pramoedya Ananta Toer, Nyangi Sunyi Seorang Bisu, certes censuré dès sa parution en indonésien en 1995, mais néanmoins disponible : il avait été traduit et publié en néerlandais entre 1989 et 1991 et une traduction partielle en anglais a été effectuée en 1999. Pourtant, il n'en existe aucune édition française. Pourquoi ce manque d'intérêt, alors que d'autres drames, survenus dans la même région, ont un retentissement quasi-immédiat, qu'il s'agisse du Sri Lanka avec la publication dès $2016 \mathrm{du}$ formidable roman d'Anuk Arudpragasam, Un si bref mariage, ou du drame des Rohingyas, photographié par Samsul Said, de nationalité malaisienne et publié dans le numéro de la revue Jentayu ? Pourtant, depuis 2017, Le Soliloque des muets a été sélectionné par des festivals très variés, de Douarnenez au Forum des images, et retenu par Images en bibliothèque, qui regroupe plus de 800 médiathèques en France, ce qui montre bien que ce sujet touche les spectateurs... et même les plus jeunes d'entre eux puisque, présenté au festival de films d'histoire de Pessac, il y a remporté le prix Bernard Landier du jury lycéen.

Au-delà de ces interrogations, la question plus fondamentale est sans doute : ces témoignages, pour quoi faire ? Il ne s'agit pas de réparations : l'absence de tout représentant du gouvernement indonésien lors des sessions du Tribunal populaire montre qu'une telle question n'est pas à l'ordre du jour. La réparation morale elle-même, sous forme d'excuses ou de la reconnaissance des souffrances subies, ne semble pas devoir intervenir à brève échéance, alors même que les victimes, plus de 50 ans après les faits, sont âgées. La condamnation des tortionnaires ne semble pas davantage envisagée.

Certes, une société ne peut pas se construire sur l'amnésie. La reconnaissance des faits, à défaut de leur réparation, est une condition pour en éviter la répétition. On se permettra à cet égard de formuler deux regrets. Le premier concerne le Tribunal populaire, dont les déclarations - du moins celles entendues dans le film - abstraites et parfois teintées d'idéologie, contrastent avec le caractère poignant des témoignages. Le deuxième porte sur le caractère univoque des témoignages recueillis : l'un des intervenants 
nous explique qu'un des bourreaux vit aujourd'hui près de chez lui. Aurait-il accepté de s'exprimer ? On peut en douter. Il aurait néanmoins été intéressant d'assister au moins à une tentative de dialogue, même si une meilleure compréhension ne mène pas nécessairement au pardon. 